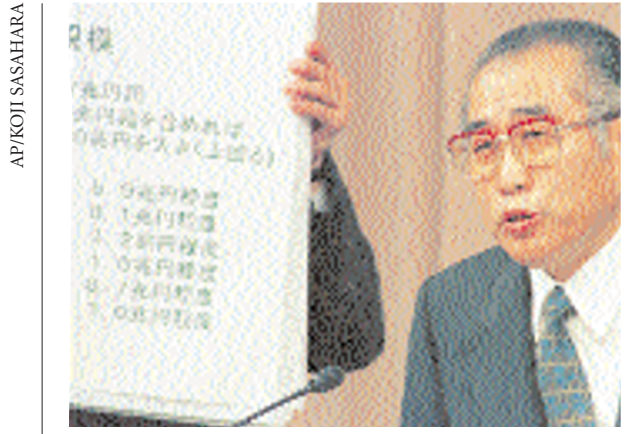

Going for growth: Japan's prime minister Keizo Obuchi unveils his new spending plans.

\section{Economic package will boost R\&D infrastructure}

[токуо] Science and technology are among the beneficiaries of the Japanese government's largest-ever economic stimulus package, which was unveiled on Monday (16 November) and aims at kick-starting the nation's ailing economy.

The package aims to create one million jobs and restore economic growth by the end of the 1999 fiscal year. The core of the measures focuses on public works projects and rescuing the ailing banking and business sector. But the government's initiative includes provisions for creating businesses through 'commercially applicable research'.

The public works projects will include the construction of new campuses at national universities and plans to build an 'international science village', a project supported by science-related ministries to create an international centre to promote scientific research (see Nature 393, 5; 1998).

The $¥ 24$ trillion (US\$204 billion) package features $¥ 8.1$ trillion for a 'social infrastructure programme' aimed at developing the infrastructure needed for areas such as telecommunications, science and technology, education and the environment.

The programme includes plans to construct information highways - a project to create fibre optic networks - and a 'nextgeneration transport' system, as well as plans to support 'future technology', especially biotechnology.

A significant portion of the funds will go towards projects linked to environmental protection, including research into the effects of endocrine disrupters which the government has listed as one of its top priorities (see Nature 392, 748; 1998).

Keizo Obuchi, Japan's prime minister, said the package is "the first step towards directing the Japanese economy back on a path of sustainable economic growth within two years". The measures are expected to be financed by the government's third supplementary budget, details of which are expected to be announced this month.

\title{
Private deal puts Japanese researcher in hot water
}

[TOKYO] Allegations of corruption involving a former professor from one of Japan's leading universities and executives of a major drug company are casting a long shadow over the government's efforts to promote collaboration between industry and the academic community.

The allegations have also thrown a spotlight on the extent to which activities considered as normal practice elsewhere are still regarded with suspicion in Japan.

Akihiko Otsuka, the president of Otsuka Pharmaceutical Co., one of Japan's largest drug companies, was arrested last week over payments made to Hiroyoshi Hidaka, a former professor at Nagoya University Medical School. Hidaka is said to have received large sums for providing 'technical consultation' for the development of drugs.

Hidaka, one of Japan's leading pharmacologists, had already been indicted in August for accepting money from two other drug companies - Fuji Yakuhin Co. and Nippon Shinyaku Co. - from which he received $¥ 124$ million and $¥ 60$ million (US $\$ 1$ million and US\$490,000) respectively. The two companies, like Otsuka, claim that the payments were 'technical guidance fees' related to drug research and development.

The arrests of Otsuka and two senior executives from the company's drugs development division have shocked Japan's pharmaceutical industry, and fuelled media criticism over suspected corruption and cronyism between industry and universities.

According to Nagoya District Prosecutor's Office and the prefectural police, the three are suspected of paying Hidaka $¥ 72$ million between 1995 and 1998 through a 'dummy' medical research company run by an acquaintance of the former professor.

Hidaka, who resigned from Nagoya University four days before his arrest in August, faced a fresh warrant last week for allegedly taking the money from Otsuka. The company is said to have approached Hidaka in 1993 to carry out collaborative research to develop a drug to replace its best-selling anti-platelet therapy — which Hidaka had helped to develop - before its patent expired in 1999.

According to allegations in the investigators' report, Hidaka conducted experiments within the university and provided the company with data on the development of the new drug, as well as allowing researchers from Otsuka to carry out research using facilities at the university laboratory.

Such activities are forbidden under Japanese law, which prohibits employees of national universities from taking part in profit-making activities. Also prohibited are exploitation of university facilities, equipment and/or staff for commercial purposes, and any involvement of industry researchers in activities other than private research.

Investigators are describing the money paid to Hidaka as "bribes" on the basis that he accepted payments in return for allowing companies to exploit university facilities for commercially-orientated research, and because the dummy medical company to which the companies paid the fees did not provide technological training as it claimed.

Otsuka and his two employees have acknowledged paying the money, but deny that it constituted a bribe. "The payments were based on a formally signed contract and memorandum to obtain technological guidance (from Hidaka), and were never meant to be bribes," said a managing director of Otsuka last week.

But he later added: "While we did not consider any of the agreement we made as being corrupt, most of us were aware that it could easily trigger misleading ideas."

The Ministry of Health and Welfare has expressed concern over the incident, saying that the suspected corruption could affect the nation's trust in the safety and reliability of pharmaceutical products.

"It is regrettable that such cronyism existed between pharmaceutical companies and a basic researcher. It is important that industry and researchers act morally and stick to the rules when they carry out collaborative research," says a health ministry spokesman.

Hidaka received a warning from the Ministry of Education, Science, Sports and Culture (Monbusho) in 1985 for carrying out similar activities involving collaborative research with pharmaceutical companies.

"It is ironic that Hidaka and the company executives have been arrested at a time when the government is placing so much effort in promoting university/industry collaboration," says one professor from Osaka University Medical School. "What they are alleged to have done was not necessarily uncommon; it seems that they were at the wrong place at the wrong time."

Since a law promoting collaboration between universities and industry was passed in May, Monbusho and the Ministry of International Trade and Industry have worked towards relaxing the civil service law to encourage ties between university researchers and industry (see Nature 390, 105; 1997).

But scientists say the status of researchers at national universities needs to be clarified. Otherwise they will not be able to differentiate the thin division between 'collaboration' and 'corruption'.

AsakoSaegusa 